\title{
AWARENESS OF CLINICAL FACULTY ABOUT NATIONAL ANTIBIOTIC TREATMENT GUIDELINES
} Rano Mal Piryani ${ }^{1^{*}}$

${ }^{1}$ Department of Internal Medicine \& Medical Education, Chitwan Medical College, Bharatpur Nepal.

*Correspondence to: Rano Mal Piryani Department of Internal Medicine \& Medical Education, Chitwan Medical College, Bharatpur Nepal. Email: r_piryani@gmail.com

\begin{abstract}
Ministry of Health and Population, Government of Nepal produced National Antibiotic Treatment Guidelines in 2014. With the objective to assess the awareness about national antibiotic treatment guidelines among the clinical faculty of Chitwan Medical College Teaching Hospital Bharatpur Nepal, a survey was conducted in January 2016 utilizing questionnaire contained demographic information and questions related to awareness. Out of 60 clinical faculty members, 39 (65\%) participated; their age was $37.5 \pm 10.9$ years, $87 \%$ were male. Only seven $(17.95 \%)$ participants were aware of the guidelines; five among them even don't know content. It seems that majority of the clinical faculty was not aware of national antibiotics treatment guidelines. This survey has its limitation as this is done only among clinical faculty of one tertiary care hospital. There is need of country wide survey on how these guidelines are being implemented as Nepal has to fulfill its commitment to achieve targets by 2020 .
\end{abstract}

Keywords: Antibiotics, Awareness, Guidelines, Faculty, Nepal

\section{INTRODUCTION}

Antibiotics have been one of the major discoveries of medical sciences in 20th century that has revolutionized the medical practice. ${ }^{1,2}$ Antibiotics are among the most frequently prescribed medicines but often misused leading to the development of resistance. ${ }^{3}$ Antibiotic resistance is one of the major public health problems of 21st century. ${ }^{4}$

World Health Organization (WHO), South Asia East Regional Office (SEARO) developed regional strategy of prevention and containment of antimicrobial resistance for 2010-2015. The goal of guiding principles is to minimize the morbidity and mortality due to antimicrobial resistance infections and to preserve the effectiveness of antimicrobial agents in the treatment and prevention of microbial infections. WHO, South Asia East Regional Office proposed some indicators and targets to meet by 2015. ${ }^{5}$ As Nepal initiated the program quite late and National Antibiotic Treatment Guidelines (NATG) was published by Ministry of Health and Population, Government of Nepal in 2014, so the target year advanced by five years to be achieved by 2020 . Ministry of Health and Population, Government of Nepal in 2014 expected that the implementation of these guidelines at hospitals which contribute significantly rational use of antibiotics and prevention and containment of antimicrobial resistance. The content of these guidelines focus on antibiotic used in treatment in general medicine, surgery, pediatrics, gynecology and obstetrics, ophthalmology, ENT, dental and sexually transmitted diseases. ${ }^{6}$

In 2015 WHO initiated World Antibiotics Awareness Week to create awareness among public, healthcare delivery professionals and healthcare policy makers about antibiotics and its resistance and encourage best practices. ${ }^{7}$ Global Antibiotic Resistance Partnership (GARP-Nepal) organized 1st annual antibiotic awareness week in Nepal during November 16-22, 2015 with the theme "Antibiotics: Handle with care" and arranged various activities including learning session for students about antimicrobial resistance (AMR). ${ }^{8}$

With relevance to awareness about the antibiotics, 
author decided to do summary survey about national antibiotic treatment guidelines. So the objective of this study was to assess the awareness about national antibiotic treatment guidelines among clinical faculty of Chitwan Medical College Teaching Hospital (CMCTH) Bharatpur, Nepal.

\section{METHODS}

Survey for the awareness of clinical faculty members about national antibiotic treatment guidelines was done among the clinical faculty members of Chitwan Medical College Teaching Hospital, in January 2016. Data was collected with consent utilizing summary questionnaire contained brief demographic info (age, sex and department of faculty) and questions related to awareness.

Questions related to awareness were:

- Are there NAT Guidelines Nepal? Yes No don't know

- If yes, then when these guidelines were published and disseminated?

- If yes, what is content of these guidelines?

- If yes, do you follow these guidelines in practice? Yes No

- If no, is there need of guidelines?

Yes No

The collected data was entered in IBMS SPSS version 21 for analysis. Descriptive analysis were done.

\section{RESULTS}

Out of 60 clinical faculty members working in Chitwan Medical College, Teaching Hospital, Bharatpur, Nepal at that point in time (January 2016). Nearly two thirds of clinical faculty $(\mathrm{N}=39 . \% 65)$ volunteered for the participation in survey. Their age was $37.5 \pm 10.9$ years (minimum 25, maximum 69); males were 34 (87\%) while females $5(13 \%)$. Among the participants $18(46 \%)$ were from surgery and allied departments, $11(28 \%)$ from medicine and allied department and $10(26 \%)$ from dentistry.

Seven (17.95\%) participants mentioned that national antibiotic treatment guidelines are there,
28 (71.80\%) stated No, while 4 (10.25\%) don't know. Among seven participants who mentioned guidelines are there, one revealed that these were published and disseminated ten years back, 2 stated one year back, one mentioned in 2010 AD and one in 2010-2011, one said rationale while one found somewhere in net.

Among seven participants who mentioned guidelines are there, five stated that they don't know content, one stated that these are for simple medical officers while one revealed that these are for primary and secondary care level.

Two faculty who mentioned about content of guidelines apply in practice. Thirty two faculty (28 stated no and 4 said don't know) agreed that there is need of guidelines. The participants who mentioned that he saw guidelines somewhere in net said that other guidelines are superior and worthy to follow.

\section{DISCUSSION \& CONCLUSION}

It seems that majority of the clinical faculty was not aware of national antibiotics treatment guidelines even after one and half year of publication and dissemination of these guidelines. The reasons could be varied. It is essential for the clinical faculty to get involved in implementation of national antibiotics treatment guidelines. This survey has its limitation as this survey is done only among clinical faculty in one private sector teaching hospital of district headquarter of one of the seventy five districts of Nepal. There is need of country wide survey on how these guidelines are being implemented as Nepal has to fulfill its commitment to achieve targets by 2020.6 Though efforts regarding awareness about use of antibiotic, consequence of misuse and antimicrobial resistance and its impact are under way in Nepal since the celebration of $1^{\text {st }}$ annual antibiotic awareness week in November 2015,8 but there is a pressing need to scale up the awareness campaign as to avoid misuse of antibiotic and prevent and contain the antimicrobial resistance. Healthcare professionals can play a role of stewardship for rationale use of antibiotics, practicing and promoting national antibiotics guidelines and prevention and containment of antimicrobial resistance.

\section{ACKNOWLEDGEMENT}

Author acknowledge the faculty members for their 
voluntary participation.

\section{REFERENCE}

1. National Antibiotic Treatment Guidelines Malaysia 2014. Ministry of Health Malaysia. https://www. pharmacy.gov.my/.../national-antibiotic-guideline-2014-full-versionjun.

2. Basnyat B, Pokharel P, Dixit S, Giri S. Situation Analysis: Antibiotic use and resistance in Nepal and recommendations for action. J Nepal Health Res Council May - Aug 2015; 13(30): 102-111

3. Nayak et al. Concept of antibiotic resistance among health professional students. International Journal of Medical Science and Public Health 2016; 5 (12): 2512-17

4. Abera $B$, Kibret $M$, Mulu W. Knowledge and beliefs on antimicrobial resistance among physicians and nurses in hospitals in Amhara Region, Ethiopia. BMC Pharmacology and Toxicology 2014, 15:26 